\title{
Overconfidence, Experience and Passive Investing
}

\author{
Alex Tun-Lee Foo ${ }^{1 *}$, Ahmad Nazri Wahidudin ${ }^{2} \&$ Qiu-Ting Chie ${ }^{3}$ \\ ${ }^{1}$ Department of Commerce \& Accountancy, Universiti Tunku Abdul Rahman, Malaysia \\ ${ }^{2}$ Department of Finance, Universiti Tunku Abdul Rahman, Malaysia \\ ${ }^{3}$ Department of Psychology and Counselling, Universiti Tunku Abdul Rahman, Malaysia \\ Email:alexfoo@utar.edu.my
}

DOI: https://doi.org/10.37134/jcit.vol10.sp.3.2020

Cite this paper (APA): Foo, A. T.-L., Wahidudin, A. N., \& Chie, Q.-T. (2020). Overconfidence, Experience and Passive Investing. Journal of Contemporary Issues and Thought, 10, 25-35. https://doi.org/10.37134/jcit.vol10.sp.3.2020

\begin{abstract}
The purpose of this paper is to consider the role of overconfidence and personal experience in adoption of passive investment style. Literature review on overconfidence, experience and passive investing are provided, followed by discussion on prospect theory and naïve reinforcement theory. Proposed conceptual framework is provided to guide future research. Anecdotes and proxy of personal experience showed that investor's personal experience might lead to different investment behavior. Overconfidence might interact with personal experience in investing context. Proposition on whether an increasing passive investing trend is a result of lower overconfidence is made. Investor's behavior on passive investing trend requires attention. The interaction between overconfidence and personal experience in light of prospect theory and naïve reinforcement theory provides insight on adoption of active / passive investing style. This paper addresses whether overconfidence is diminished in light of global passive investing trend. This paper also stresses the importance of personal experience in investment decision.
\end{abstract}

Keywords: Losing Money; Prospect Theory; Miscalibration; Investment Style

\section{Being Human}

Coined by Richard Thaler as the Econs, the fictional agents act with the only agenda to maximize their own satisfaction in the economic context. This includes personal investing where the investors are faced with myriads of options to maximize their returns. Prior experience is regarded as sunk cost to rational finance, but what about behavioral finance? It appears that the imperfect human, apart from overconfidence issue, cling on their past experience as they go about business. This paper addresses overconfidence in light of investor's personal experience.

In the investing context, there appears to be a shift of investment style, both institutional and retail, from active to passive investing. Why is there a preference on passive investing? To illustrate the magnitude of difference, nearly half of the passively managed investment funds (retail and institutional combined) now own half of the U.S. equity market. A decade ago, this percentage is only around a quarter of the market share. In other words, passive fund industry is growing at a size that warrants serious attention by the finance academics. As active investing is 
always associated with overconfidence, a shift in passive investment style begs a question. Could it be that the passive investors are finally free from the overconfident spell?

The paper discusses overconfidence, experience and passive investing. Prospect theory and naïve reinforcement theory are presented prior to proposing a conceptual model to guide future research.

Like all of life's rich emotional experiences, the full flavor of losing important money cannot be conveyed by literature... nor can any description that I might offer here even approximate what it feels like to lose a real chunk of money that you used to own'.

Fred Schwed, the author of Where Are the Customers' Yachts?

\section{The Confident Investor}

Popularly coined as overconfidence, investors overestimate their ability to pick the next stock winners. As stock price is a function of many factors which are outside of investor's control, being overconfident in stock selection is a sub-optimal financial behavior that can lead to financial losses. Papers discussing why even the best experienced mutual fund managers underperform the market are not novel (Glode 2011). Both 'wall-street' portfolio and hedge fund managers and the 'main-street' retail investors exhibit overconfidence by believing that they can do better than their peers.

Overconfidence is mainly a result of two functions. According to Kahneman (2011), the ability of our mind to establish a coherent story and the ease of retrieving that story reinforce our confidence toward something. In other words, how confident a person can be depends on how well constructed the logical thought, and how easy it is to retrieve that thought through repetition and reinforcement. Kahneman (2011) explained that when uncertainty exists, people may reach different conclusion due to relative, arbitrary reference point. In investing context, an overconfident investor is someone who thinks by his own analytical ability he is able to forecast the market move and then profit from it.

Overconfidence bias is also seen as a manifestation of other behavioral biases. An overconfident investor exhibits illusion of control, a bias that put investor "in charge" of things he actually has little influence on. For example, an investor might feel that the future stock price movement is largely depending on his technical analysis skill. Confirmation bias follows suit as he selectively filter information that affirms his pre-existing beliefs.

Overconfidence is boasted to have a reputation of decades of research. However, there appears to be a lack of consensus on measuring overconfidence in the financial contexts. Multiple opinions were available on how overconfidence should be measured. For example, Durand et al. (2013) used trading frequency as proxy to overconfidence. Barber and Odean (2001) substituted gender as proxy to overconfidence. As male generally exhibits higher level of testosterone, it motivates overconfident behavior. However, Fung and Durand (2014) contended that male stereotype as being overconfident should not be established as the key predictor should be psychological masculinity. For paper-based assessment, Pompian (2011) proposed a 8-question questionnaire measuring both prediction and certainty facet of overconfidence. Other questionnaire-based works ranged from single-item (Pan and Statman 2012) to 18 questions 
(Michailova and Schimdt, 2016). For example, the latter study measures participants 'hit-ratio', a term referring to accuracy of answer expressed in confidence percentage (e.g., $50 \%$ sure, or $60 \%$ sure).

The confidence people have in their beliefs is not a measure of the quality of evidence but of the coherence of the story the mind has managed to construct. Daniel Kahneman, the 2002 Nobel Laureate, in his book 'Thinking, Fast and Slow'

\section{The Experienced Investor}

Among the established personal finance literature includes lifecycle investing, age-based investing, and investing based on one's ability, needs, and willingness to take risk. While these are legitimate predictors in investment decision, anecdotes suggest that the investors often capitulated in times of abnormal market volatility. In other words, what was once decided to be a suitable portfolio based on personal risk assessment no longer becomes appropriate as the market tests the limit of investors in actual market downturn. In times of prolonged, severe market downturn, the investors push for sell button.

Schwed (1940) classic work on 'Where are the Customer's Yachts?' provided a glimpse of the importance of actual experience in investing. Notably, the experience of losing significant amount of money is one significant financial event affecting investors. Actual experience helps to reveal real risk tolerance. Research on significant financial events help to advance the proposition of experience on investing. For example, for the past 100 years in the financial industry, the world has witnessed great depression (1929), high interest rate (1980s), Asia financial crisis (1997), dotcom bubble (1995-2001), and subprime mortgage crisis (2008-2009). Malmendier and Nagel (2011) traced the generation who had personally experienced the early 1930s Great Depression in the U.S. It was subsequently revealed that these group of people struggle to involve themselves in risk taking activities even after a span of four decades. Similar report by Ehrmann and Tzamourani (2012) in a sample consisting of 50,000 surveys across 23 countries. In scenarios where hyperinflation hit as high as $20 \%$, these experiences further discouraged investor's risk preferences in the future.

The importance of experience in financial decision slowly gained traction. Klement (2015) advocated the use of financial diary or amnesia. This presupposes that the financial experience in the past can help to inform their future decision. Andersen et al. (2019) in the context among Denmark investors analyzed how personal experience can impact financial decision. The study was set in context of subprime mortgage crisis affecting bank stocks in regions where the participants lived. Using the unique categorization of personal experience (first-hand, secondhand, third-hand experience), it was found that financial losses experienced directly or personally can lead to a more conservative approach of investing. Meanwhile, the effect of financial loss experience proxied by close relatives or geographical location is milder.

...life experiences are an important - if not the most important - contributor to financial risk preferences. (Klement, 2015) 


\section{The Passive Investor}

Investing comes with different approaches. Zehndorfer (2018) documented a trading frequency continuum as a way to differentiate different types of investing styles from scalping, day trading, position and swing trading, to buy-and-hold investing. For long-term investing, major school of thoughts include value investing, growth investing, momentum investing, mutual fund investing and index investing. Index investing is a 'passive' method that allows investors to own a particular market by purchasing a mutual fund that rides on that index. An example of index would be Standard and Poor 500 (S\&P 500). S\&P 500 combines all large and some mid-cap US companies in a basket. The passive fund manager purchases stocks according to their market capitalization, hence achieving a replication mimicking the index performance.

When index investing was started by John Bogle in 1976, it did not sit well with the financial industry. The index fund project was labelled as a 'Bogle's Folly', and 'un-American'. Four decades later, it is clear that index investing is a formidable investing strategy judging by the size of funds it attracts across the globe. For the first time in 2019, total money in passive funds exceeds the active funds combined. This is the trend that should not be ignored, both at institutional and retail level.

Index investing appears to be a promising investment vehicle for the masses due to broad diversification with low cost maintenance. First, index investing allows mass diversification (often up to few hundreds to thousands of stocks), which significantly reduces risk and volatility. Active fund do hold a number of stocks too. However, the number is smaller (often no more than 50 stocks) as each handpicked stock will require research and monitoring. Second, the cost of maintaining a passive fund is significantly lower. The reason is that the passive fund essentially mimics the index. This allows cost saving such as fees for market and stock research.

Value investing is based on the premise that stocks are not always valued fairly by the market participants. A stock can sometimes be priced significantly lower than its book value. This may be due to gloomy prospect of the business, industry trend, major events that cast a bad outlook for that particular stock. Growth investing looks into the earning prospect of the company. A growth stock should have key characteristics such as (1) promising outlook, (2) improved earnings record, and (3) significant expansion. A growth investor normally looks at financial history of the stock, and qualifies them when there is a pattern that the earnings are likely to be improved over time.

Momentum investing combines the technical aspect of trading with fundamental data. Recognizing that momentum is one anomaly observed by the proponents of efficient market, investors capitalize on stock trend to plan and execute their buy-and-sell decisions. Momentum investing normally has a fairly short period of investing horizons, ranging from the longest 5 years to the shortest 3 weeks depending on investor's strategies. Mutual fund investing allows the investors to pool their money under an investment manager who will then manage the fund on their behalf. This method depends on the manager's skill in seeking to outperform the market. Variants of mutual funds include sector fund that allows investors to get exposed to a certain market. A mutual fund typically charges an upfront fee with annual management fee as service rendered to their investing clients. For dichotomous classification, value, growth, momentum and 
mutual fund investing are categorized as active investment style. Index investing is categorized as passive investment style.

Individual's portfolio return is an important criterion variable in understanding behavioral finance. However, investor's return can be a combination of skill and luck, probably even higher emphasis on the latter (Shefrin 2002). Additionally, short-term performance is not an indicator for long-term result. In view of random-walk perspective on the market, this study digresses from actual portfolio return to expression of investment style instead.

"Don't look for the needle in the haystack. Just buy the haystack!"

John Bogle, the founder of first index fund in 1976

\section{Overconfidence and Passive Investing}

The overconfident investors believe in their own judgment and ability to time the market or a particular stock trend. Market return, i.e., index-tracking performance is then often used as a benchmark from which the active investors judge whether they 'outperform' or 'underperform' the market. Since money flow from active to passive funds continues to increase, does it mean that the investors have lose faith in active investing? Is abandonment of active investing an indication of reduced overconfidence phenomenon in the market? These are interesting questions worth studying.

The general notion that human is overconfident cannot be overlooked. Hence, there is a strong belief that overconfidence remains its root in humanity even as passive investing is thriving. However, overconfidence and passive investing are antithetical to one another. Following the random-walk theory, can we say that the human agents have finally come to their sense that the only way to navigate in the stock market is by long-term holding of passive funds? They appear to be more rational (at least in this respect), which is the central theme of behavioral finance. Comparative study between passive and active investor behavior appears to be of little coverage at this point of writing.

Passivity is a known behavioral bias. Sometimes known as 'inertia', human is especially good at maintaining status quo, or doing the same thing. Having an investment strategy in a convenient, default way is one positive exploit used by the behavioral nudges such as 'Save More Tomorrow' program (Thaler \& Benartzi, 2004). The increase in passive fund participation can be due to more default switch of employee contribution, for instance. As default choice is switched from active to passive funds, it facilitates committed money flow to the passive funds. Other than that, more retail and institutional investors might have started to embrace the beauty of index investing. If so, overconfidence appears to reduce.

This paper posits that passive investors should exhibit lower overconfidence than their active counterparts. Whether this 'lower' overconfidence is achieved by means of cognitive function (i.e., index investing outperforms active funds after cost), or an emotional one (i.e., I have an edge in the market) warrants further study. 


\section{Overconfidence and Experience}

Allen \& Evans (2005) in an experimental research involving 109 respondents suggested that experience has little effect on overconfidence. Between experienced and inexperienced gamblers, there appears to be of little effect on their tendency to get overconfident. This is contrary with previous finding by Gervais and Odean (2001), which proposes that experience via feedback of a repeated task might reduce overconfidence. The interaction between overconfidence and personal experience will be further elaborated in the context of prospect theory and naïve reinforcement theory.

\section{Prospect Theory and Naïve Reinforcement Theory}

Considering social science as an art, there are separate viewpoints in regards to decision. The first is the Prospect Theory. In events where one is asked to choose between two positive options, the risk adverse option is preferred. On the other hand, when faced between two negative options, the risk seeking option is selected. From a financial perspective, a person seeks a conservative option to protect profit (between positive options), and an aggressive option to minimize loss (between negative options). Table 1 is constructed as a visual summary.

Experience without theory is blind, but theory without experience is mere intellectual play. Immanuel Kant

Table 1: Motivated Behavior according to Prospect Theory

\begin{tabular}{cc}
\hline Scenarios & Motivated Behavior \\
\hline Choose between two positive options & Risk averse \\
Choose between two negative options & Risk seeking \\
\hline
\end{tabular}

Major social learning theory, particularly naïve reinforcement theory, suggests that a favorable outcome leads to similar decision style or option in future. This means a win in the stock market will further fuel the tendency to bet again, often in a greater magnitude than the last. Likewise, an unfavorable outcome leads to reconsideration of previous options, which leads to smaller bet or changing strategy. Since a win is considered a prior gain, this positive experience motivates subsequent bigger bet (see table 2). The hot-hand winner will exhibit risk seeking behavior.

Table 2: Personal Experience and Subsequent Motivated Behavior according to naïve reinforcement theory

\begin{tabular}{cc}
\hline Scenarios (Experience) & Subsequent Motivated Behavior \\
\hline A previous win & Bigger bet in similar fashion \\
A previous loss & Smaller bet (or changing strategy) \\
\hline
\end{tabular}


Combine naïve reinforcement theory with prospect theory might lead to further insight. As the phrase suggests, 'reinforcement' can be positive or negative given the scenarios, and 'prospect' deals with predicted outcome between dichotomous options. For simplicity sake, prospect theory assumes unified prior experience of participants. However, as people garner different personal experiences over time, these memories are influential in future decisions. For example (as illustrated below), a person with prior losing experience tends to exhibit risk adverse behavior. Conflict exists when he is subsequently encountered with a 'prospect' which requires him to decide between two negative options. Naïve reinforcement theory suggests maintaining risk adverse behavior, while prospect theory posits a risk seeking behavior.

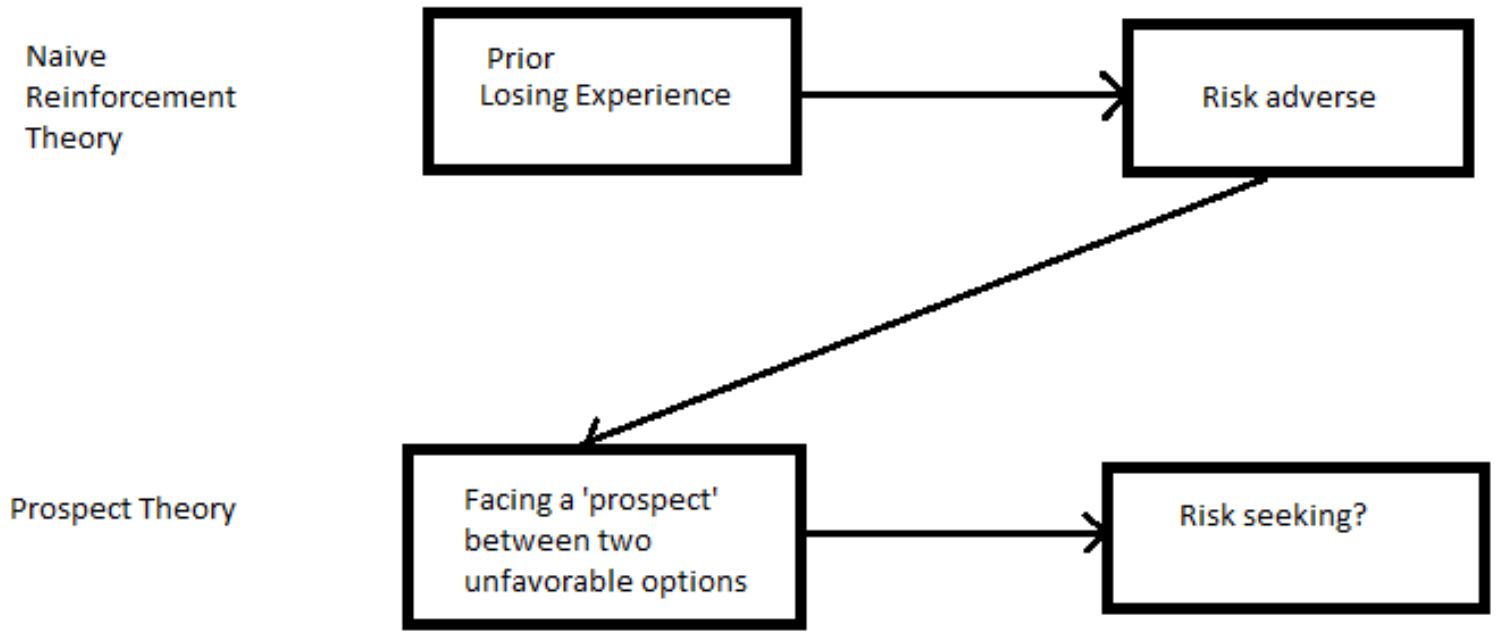

Figure 1: Naïve Reinforcement Theory and Prospect Theory

Prospect theory suggests that in the domain of losses, people prefer gamble over sure things. From the viewpoint of personal investing, a significant financial loss is a painful memory as it sets the investors years back from planned retirement or important financial goals in life. It is unsure if prior experience is so significant that can lead to risk adverse behaviors in years, or even decades to come. Research on great depression reveals that generation who lived to experience that financial horror consistently exhibit low risk taking activities. Can human, in view of prospect theory, free from the bias of prior experience in decision making?

A win signifies a cognitive alignment that an executed strategy leads to a favorable outcome. This helps build confidence as coherent stories are increasingly easily retrieved through repetition and in greater magnitude. Meanwhile, a loss causes cognitive dissonance, which temporarily disrupt the coherent stories previously built in the cognitive realm. If confidence is drawn from coherent stories, then a series of past events cemented as memory becomes an important cue that the behavioral finance should not ignore.

As informed by the literature, experience plays a role in investment decision. The criterion variable of the study is digressed from the actual portfolio performance to expression of styles instead. Particularly, a dichotomous active/passive style is adopted in light of increasing shift of 
money flow from active to passive fund industry. A simpler conceptual model factoring personal experience will include overconfidence, a prominently studied behavioral bias that warrants further research. Overconfidence is posited to lead to different investment style, and such difference may be moderated by investor's personal experience. A visual presentation on overconfidence, experience and investment style is provided, which will serve as proposed conceptual model.

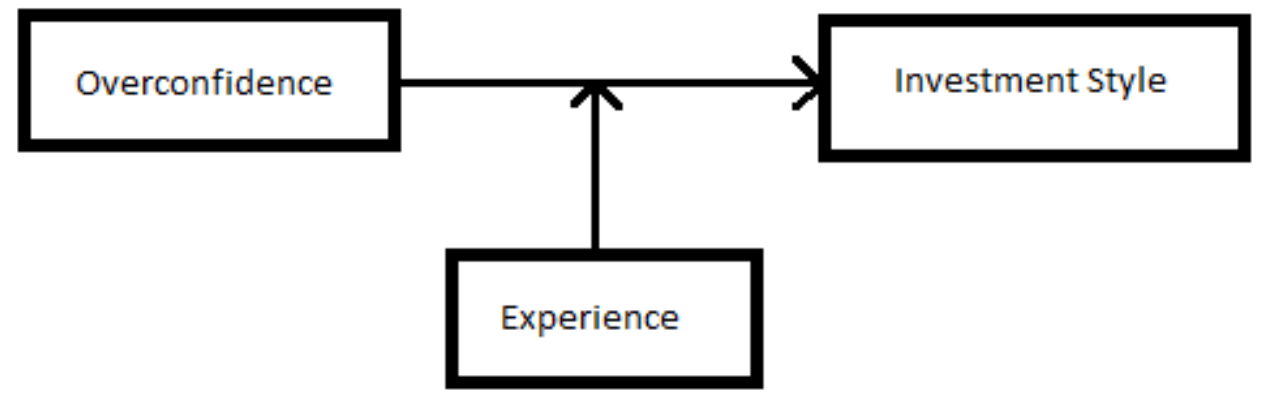

Figure 2: Developed for research

Both overconfidence and personal experience are categorized into two groups respectively. This allows $2 \times 2$ matrix with possible interpretation on each combination. For simplicity sake, only a subset of interpretation will be included. Table 1, 2 and 3 are shown only from a naïve reinforcement perspective.

Table 3: Overconfidence and personal experience through the lens of naïve reinforcement theory

\begin{tabular}{|c|c|c|}
\hline \multirow[b]{2}{*}{ Personal Experience } & \multicolumn{2}{|c|}{ Overconfidence } \\
\hline & Low & High \\
\hline Significant gain (positive) & & Risk seeking \\
\hline Significant loss (negative) & Risk adverse & \\
\hline
\end{tabular}

Table 3 showed a matrix between overconfidence and experience. Investors with high pre-existing overconfidence level and positive experience are likely to exhibit risk seeking behavior in the future. Potential behaviors might observe a higher asset allocation into volatile, aggressive investment instruments under the active investment style category. On the other hand, investors with low pre-existing overconfidence level and prior experience in significant financial loss are likely to exhibit risk adverse behavior in the future. Potential behaviors under this category can be in the form of conservative asset allocation away from equity-based portfolios, or an adoption of passive investment style. Table 4 featuring $2 \times 2$ matrix on overconfidence and investment style is shown below.

Table 4: Overconfidence and investment styles through the lens of naïve reinforcement theory

\begin{tabular}{cccc}
\hline & & Overconfidence & High \\
\hline Investment Style & Low & x \\
\hline Active & $x$ & \\
Passive & & & \\
\hline
\end{tabular}


Investors with high pre-existing overconfidence level are likely due to their heightened expectation of outperformance adopt an active investment style. Potential behaviors include a heavier asset allocation in individual stocks or active mutual funds. As overconfidence level drives high, so does the investor's expectation to outperform the market. Conversely, investors with low pre-existing overconfidence level will likely adopt a passive strategy. This is due to their rational expectation in their ability to outperform the market. Observed behaviors might include a heavier asset allocation in passive funds, reduced individual stocks participation, or even withdrawal from the equity market.

Table 5: Personal experience and investment styles through the lens of naïve reinforcement theory

\begin{tabular}{ccc}
\hline Investment Style & Personal Experience & Significant Loss \\
\hline Active & Significant Gain & Withdrawal \\
Passive & Continue & Withdrawal \\
\hline
\end{tabular}

Table 5 showed $2 \times 2$ matrix incorporating personal experience and investment style is constructed. The investors maintain or shift their investment styles in response to how they react to significant financial events. In event of significant gain, this will likely further motivate the current action as proposed by naïve reinforcement theory. Prospect theory further suggests that in events of deciding between two positive options, it will result in risk adverse behavior. Potential moves include a shift of financial assets from a higher risk-reward equity to lower risk-reward fixed income.

In event of significant loss, this will likely trigger avoidance behavior as the investors try to minimize similar behavior that invite repeated regret and punishment. In line with naïve reinforcement theory, both active and passive investors might see reduced exposure in equity in reaction to the prior losing experience. For prospect theory, risk seeking behavior is triggered when faced with two negative options. As investors try to break-even or minimize their losses, they become more aggressive in financial decision. This might translate to the use of leverage, a greater asset allocation into the equity, and heavier emphasis of high volatility instruments such as penny stocks, forex derivative, and options.

There can be situations where the investors had both positive and negative experiences. This paper aims to be brief, hoping to spark research interest in this area. How does the investors react when they possess both prior gain and prior loss experience? Does losing experience, as Prospect Theory suggests, overshadow the winning experience? How does these experience interact and moderate their level of overconfidence, which in turn affect their investment style?

\section{Suggestion for Further Work}

Suggestions for extension of study can include antecedent of overconfidence. For example, Durand et al. (2013) proposed personality as the well-spring of investment behavior. Personality is generally studied as individual differences, and it comes with different perspectives. Personality dimensions were further split into the Big Five (McCrae \& Costa, 2003), and Big Three (Eysenck 2017). There is also alternate model such as Myers-Briggs Personality Inventory (Myers 
et al. 1998). An alternate personality model such as the neuropsychological perspective by BIS/BAS instrument might help to provide useful insights.

Example of empirical evidence studying the result of personality toward overconfidence includes Schaefer et al. (2004) and Durand et al. (2013). In general, extrovert exhibits higher trading frequency, which means greater confidence in making investing decisions. Evidence showing the effect of personality toward investment decision includes Oehler et al. (2018), Gambetti \& Giusberti (2019), and Fung \& Durand (2014). Meanwhile, evidence pointing personality toward investment style includes Pompian \& Longo (2004), Durand et al. $(2008,2013)$ in the form of choice and outcome. More importantly, two dimensions, i.e., extroversion and neuroticism received increased attention in behavioral finance literature. It suggests a narrower focus of personality dimensions in predicting behavioral biases (see Durand et al., 2018, Oehler et al. 2018 as examples). Nicholson et al. 2005 relate how extroversion and neuroticism lead to different risk-taking decisions. Particularly in financial decision, high extroversion and low neuroticism were observed in engaging risky financial decisions. Durand et al. (2013) found that overconfidence correlate with investor's personality traits. The interesting study by Schaefer et al. (2004) revealed correlation between subject's extroversion and confidence. However, confidence does not translate to accuracy.

\section{Concluding Remark}

'The best way to measure your investing success I not by whether you're beating the market but by whether you've put in place a financial plan and a behavioral discipline that are likely to get you where you want to go.' Benjamin Graham, the Father of Value Investing

Recent Nobel prizes recognizing behavioral finance as a recognized field might give an impression that it is still young. In fact, Richard Thaler traced the work of behavioral finance back to Adam Smith. Respected guru of value investing, Benjamin Graham also hinted on the importance of behavioral aspects in personal investing. This paper pulls together investor's overconfidence, experience, and investment style. Adaption to this model is encouraged especially in area that involves investor's past experience in risk profiling. Research outcome, if positive, should provide greater awareness on the importance of personal experience in personal wealth management practice.

As active retail investing is still an important piece of ensuring overall financial health of the market, time will tell if passive investing trend will continue in the next decade. For now, the need to understanding the difference and shift between active and passive investment style is perhaps long overdue.

\section{References}

Allen, W.D., \& Evans, D.A. (2005). Bidding and overconfidence in experimental financial markets. The journal of behavioral finance, 6(3), 108-120.

Andersen, S., Hanspal, T., \& Nielsen, K.M. (2019). Once bitten, twice shy: The power of personal experiences in risk taking. Journal of Financial Economics, 132(3), 97-117. 
Barber, B.M., \& Odean, T. (2001). Boys will be boys: Gender, overconfidence, and common stock investment. The quarterly journal of economics, 116(1), 261-292.

Durand, R. B., Fung, L., \& Limkriangkrai, M. (2019). Myopic loss aversion, personality, and gender. Journal of Behavioral Finance, 20(3), 339-353.

Durand, R., Newby, R., Tant, K., \& Trepongkaruna, S. (2013). Overconfidence, overreaction and personality. Review of Behavioral Finance, 5(2), 104-133.

Durand, R.B., Newby, R., \& Sanghani, J. (2008). An intimate portrait of the individual investor. The Journal of Behavioral Finance, 9(4), 193-208.

Ehrmann, M., \& Tzamourani, P. (2012). Memories of high inflation. European Journal of Political Economy, 28(2), 174-191.

Eysenck, H.J. (2017). The structure of personality. In The Biological Basis of Personality. Routledge.

Fung, L., \& Durand, R.B. (2014). Personality traits. Investor behavior: The psychology of financial planning and investing, 99-115.

Gambetti, E. \& Giusberti, F. (2019). Personality, decision-making styles and investments. Journal of Behavioral and Experimental Economics, 80, 14-24.

Gervais, S. \& Odean, T. (2001). Learning to be overconfident. The Review of Financial Studies, 14(1), 1-27.

Glode, V. (2011). Why mutual funds “underperform”. Journal of Financial Economics, 99(3), 546-559.

Kahneman, D. (2011). Thinking, fast and slow (Kindle Edition). Macmillan.

Klement, J. (2015). Investor Risk Profiling: An Overview. CFA Institute Research Foundation.

Michailova, J., \& Schmidt, U. (2016). Overconfidence and bubbles in experimental asset markets. Journal of Behavioral Finance, 17(3), 280-292

.Malmendier, U., \& Nagel, S. (2011). Depression babies: do macroeconomic experiences affect risk taking?. The Quarterly Journal of Economics, 126(1), 373-416.

McCrae, R.R. and Costa, P.T. (2003). Personality in adulthood: A five-factor theory perspective. Guilford Press.

Nicholson, N., Soane, E., Fenton-O'Creevy, M. and Willman, P. (2005). Personality and domain-specific risk taking. Journal of Risk Research, 8(2), 157-176.

Oehler, A., Wendt, S., Wedlich, F. and Horn, M. (2018). Investors' personality influences investment decisions: Experimental evidence on extraversion and neuroticism. Journal of Behavioral Finance, 19(1), 30-48.

Pompian, M.M. (2011). Behavioral finance and wealth management: how to build investment strategies that account for investor biases (Vol. 667). John Wiley \& Sons.

Pan, C.H. and Statman, M. (2012). Questionnaires of risk tolerance, regret, overconfidence, and other investor propensities. Journal of Investment Consulting, 13(1), 54-63.

Pompian, M.M. and Longo, J.M. (2004). A new paradigm for practical application of behavioral finance: creating investment programs based on personality type and gender to produce better investment outcomes. The Journal of Wealth Management, 7(2), 9-15.

Schaefer, P.S., Williams, C.C., Goodie, A.S. and Campbell, W.K. (2004). Overconfidence and the big five. Journal of research in Personality, 38(5), 473-480.

Schwed, F. (1940). Where are the Customers' Yachts?, Or, A Good Hard Look at Wall Street (p. 212). New York: Simon and Schuster.

Shefrin, H. (2002). Beyond greed and fear: Understanding behavioral finance and the psychology of investing. Oxford University Press on Demand.

Thaler, R.H. and Benartzi, S. (2004). Save more tomorrow ${ }^{\mathrm{TM}}$ : Using behavioral economics to increase employee saving. Journal of political Economy, 112(1), 164-S187.

Zehndorfer, E. (2018). The Physiology of Emotional and Irrational Investing: Causes and Solutions. Routledge. 